\title{
Correction of Posttraumatic Enophthalmos
}

\section{Citation}

Hazani, Ron, and Michael J. Yaremchuk. 2012. Correction of posttraumatic enophthalmos. Archives of Plastic Surgery 39(1): 11-17.

\section{Published Version}

doi:10.5999/aps.2012.39.1.11

\section{Permanent link}

http://nrs.harvard.edu/urn-3:HUL.InstRepos:10436298

\section{Terms of Use}

This article was downloaded from Harvard University's DASH repository, and is made available under the terms and conditions applicable to Other Posted Material, as set forth at http:// nrs.harvard.edu/urn-3:HUL.InstRepos:dash.current.terms-of-use\#LAA

\section{Share Your Story}

The Harvard community has made this article openly available.

Please share how this access benefits you. Submit a story.

Accessibility 


\title{
Correction of Posttraumatic Enophthalmos
}

\author{
Ron Hazani, Michael J. Yaremchuk
}

Division of Plastic and Reconstructive Surgery, Massachusetts General Hospital-Harvard Medical School, Boston, MA, USA

\begin{abstract}
Management of posttraumatic enophthalmos can present as a challenge to the reconstructive surgeon, particularly in cases of late presentation. This article reviews the pertinent anatomy of the orbit, diagnostic modalities, indications for surgery, and surgical approaches as they relate to the treatment of posttraumatic enophthalmos. Internal orbital reconstruction has evolved to an elegant procedure incorporating various biologic or alloplastic implants, including anatomical pre-bent implants. Successful repair of late enophthalmos has been demonstrated in multiple recent studies and is likely related to the precision with which orbital anatomy can be restored.
\end{abstract}

Keywords Enophthalmos / Orbital fractures / Orbital implants

\author{
Correspondence: \\ Michael J. Yaremchuk \\ Division of Plastic and Reconstructive \\ Surgery, Massachusetts General \\ Hospital-Harvard Medical School, \\ 15 Parkman St., WACC 435, Boston, \\ MA 02114, USA \\ Tel: +1-617-726-5280 \\ Fax: +1-617-726-2824 \\ E-mail:dr.y@dryaremchuk.com
}

No potential conflict of interest relevant to this article was reported.

Received: 30 Dec 2011 - Revised: 2 Jan 2012 • Accepted: 5 Jan 2012

pISSN: 2234-6163 • elSSN: 2234-6171 • http://dx.doi.org/10.5999/aps.2012.39.1.11 • Arch Plast Surg 2012;39:11-17

\section{INTRODUCTION}

Enophthalmos is the recession of the ocular globe within the bony orbit. Two to three millimeters of enophthalmos is clinically detectable, and more than $5 \mathrm{~mm}$ is disfiguring. The principal mechanism in its development is the displacement of a relatively constant volume of orbital soft tissue into an enlarged bony orbit [1]. Fat atrophy and scar contracture are less important factors in causing a mismatch of soft tissue and orbital volume [1-3]. Because enophthalmos most often presents with an inadequately treated orbital fracture where the orbital floor is disrupted, the condition is characteristically accompanied by inferior displacement of the globe. Recession of the globe changes the drape of the upper lid on the globe, tending to deepen the superior tarsal fold and cause a ptosis of the upper lid.

Because posttraumatic enophthalmos is primarily due to alterations in the configuration of the bony internal orbit rather than to changes in the amount or character of its soft tissue contents, the treatment strategy for restoring eye position is the anatomic reconstruction of the internal orbit. This is best accomplished by defining the location and extent of injury preoperatively with computed tomography (CT) scans, wide exposure of the injured area and retrieval of orbital soft tissues, and replacement of the invariably comminuted displaced fractures with autogenous or alloplastic material.

\section{PERTINENT ANATOMY}

The internal orbit may be conceptualized as a modified pyramid. The lateral wall consists of thick bone created by articulation of the greater wing of the sphenoid and the orbital process of the zygoma. However, the floor, medial wall, and roof can be divided into concentric thirds based on bone thickness (Fig. 1). The anterior third of the internal orbit consists of increasingly thicker bone as it merges with the orbital rim. Immediately behind the rim, the anterior third of the orbit has a concave shape, and so the widest orbital diameter is approximately 1.5 $\mathrm{cm}$ within the orbital cavity. The posterior third also consists of thick bone with relatively flat walls. The middle third consists of thin bone and allows this portion of the orbit to act as a crush

Copyright $\odot 2012$ The Korean Society of Plastic and Reconstructive Surgeons

This is an Open Access article distributed under the terms of the Creative Commons Attribution Non-Commercial License (http://creativecommons.org/

licenses/by-nc/3.0/) which permits unrestricted non-commercial use, distribution, and reproduction in any medium, provided the original work is properly cited.

www.e-aps.org 


\section{Fig. 1. Pertinent anatomy of the orbit \\ A cadaveric dissection of the orbit demonstrating the convex shape of the inferomedial aspect of the internal orbit. An average distance of approximately $40 \mathrm{~mm}$ between the inferior orbital rim and the posterior ledge of the posterior maxillary wall is shown.}

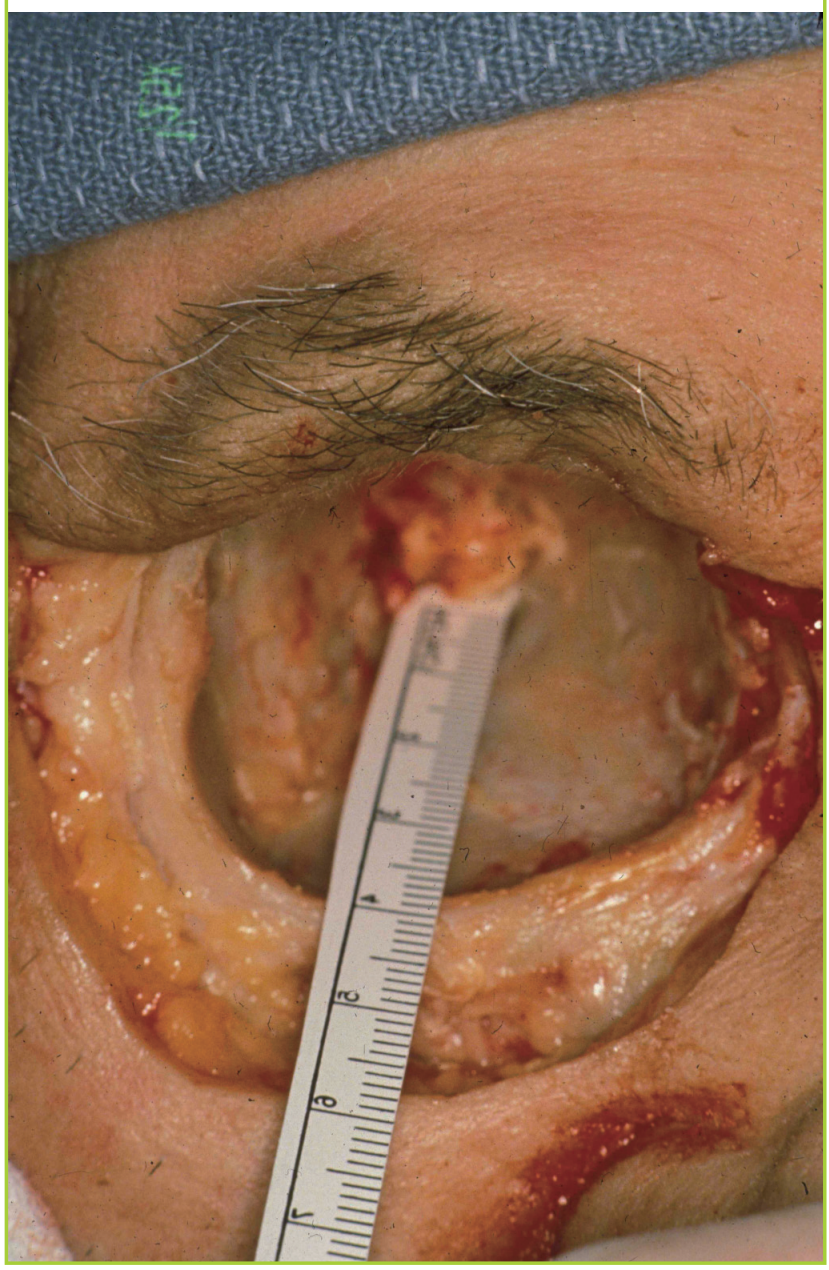

zone, thereby protecting the optic nerve and globe by absorbing impact forces (Fig. 2).

The floor of the orbit is a frequent site of fracture $[4,5]$. The floor medial to the infraorbital canal and the inferior portion of the medial wall is typically involved in the 'blow-out' fracture. This area has a convex shape that produces a constriction behind the globe. Loss of this convexity transforms the intraorbital shape from pyramidal to spherical, increasing orbital volume and tending towards enoph-thalmos.

Certain injuries, usually involving the lateral orbital wall or roof, may result in inward displacement of larger fracture segments. These 'blow-in' fractures decrease orbital volume, resulting in globe proptosis.

\section{Fig. 2. Cadaveric dissection of the orbital floor}

The disrupted orbital floor in this cadaveric specimen illustrates the thin, eggshell-like, consistency of the middle third as compared to the uninjured anterior and posterior portions of the floor.

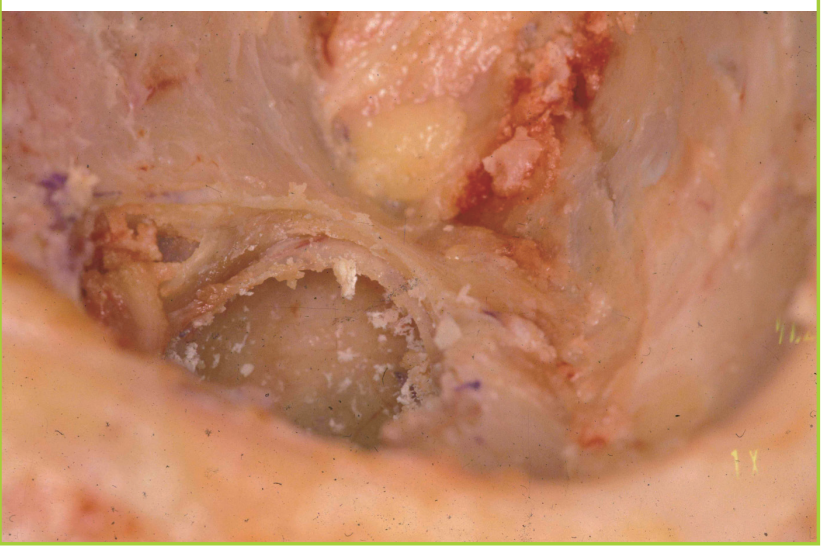

\section{DIAGNOSIS}

The clinical diagnosis of significant internal orbital disruption is based on globe malposition. When the lateral orbital rim is intact (isolated floor or medial wall blow-out fractures) and soft tissue swelling has subsided, the severity of enophthalmos can be determined with a Hertel exophthalmometer which measures the difference between the anterior corneal surface and the lateral orbital rim. In the uninjured state, the cornea extends approximately $16-17 \mathrm{~mm}$ anterior to the lateral orbital rim. Immediately after injury, however, globe position may appear normal or proptotic owing to soft tissue swelling. Radiologic imaging is therefore the key to defining the presence and extent of injury.

Plain x-rays will confirm the presence of fractures but cannot define the extent of injury or the status of the soft tissues. The ideal preoperative evaluation consists of axial, coronal, and sagittal CT sections using both bone and soft tissue windows. Thin-sliced coronal CT images allow measurement of a floor or wall defect. Defects greater than $25 \%$ of the orbital floor will result in measurable enophthalmos. Those involving more than half of the floor will result in significant enophthalmos [6]. Diplopia may result from extra muscle contusion or entrapment. A Forced duction test and a CT scan can differentiate between diplopia that results from rectus muscle entrapment and diplopia that is secondary to post injury soft tissue swelling.

\section{INDICATIONS FOR SURGERY}

In the acute phase, CT findings coupled with forced duction testing provide the best guide to the need for surgery. A CT scan 
can define the amount of floor disruption and, therefore, predict the likelihood of enophthalmos. It can also define the relation of the extraocular muscles to the fracture segments. If surgery is thought appropriate, it should be performed in the acute phase when dissection is more straightforward, and soft tissue scarring and contracture are not problems. Late or secondary reconstructions, in general, are less successful than appropriate reconstruction performed in the acute phase.

When indications for acute management are unclear, the following algorithm has been proposed. Exploration is performed if enophthalmos greater than $2 \mathrm{~mm}$ develops at any time within the first 6 weeks following injury, or if diplopia in the primary gaze or down-gaze reading position does not clear within 2 weeks [7].

In late presentations, when globe malposition is the raison d'etre, CT evaluation is critical in preoperative assessment. It defines not only the location and extent of internal orbital injuries but also any adjacent facial skeletal injuries. This is crucial in planning the operative approach and the method of reconstruction.

\section{SURGICAL TECHNIQUES}

\section{Exposure}

Proper repositioning of the globe requires exposure and anatomic reconstruction of the internal orbit. Craniofacial approaches afford exposure of both the external and internal orbit. A transconjunctival incision, often with a lateral canthotomy or transcaruncular extension is used to approach the orbital floor, as well as the medial and lateral walls. The coronal approach will provide exposure of the upper orbit. Extensive subperiosteal dissection of the lateral orbit will detach the lateral canthus. If it is detached, the lateral canthus should be repositioned at closure. The blepharoplasty subciliary skin incision and skin muscle flap are an alternative to the transconjunctival approach. The These transcutaneous lid incisions are more prone to post operative lid retraction. Insicions directly over the orbital rim at the junction of the eyelid and cheek can leave an inconspicuous scar in older individuals.

\section{Orbital rim repositioning}

Because a small change in rim position leads to a large change in orbital volume, accurate orbital rim positioning is an important first step in the reconstruction of the internal orbit. The repositioned segments are stabilized with plates and screws. In the acute setting, the fracture segments are anatomically realigned. Keys in accurate repositioning are the zygomaticosphenoid articulation and the zygomatic arch. Unlike the narrow zygo- maticofrontal articulation, the zygoma's articulation with the sphenoid is a relatively long one, making edge-to-edge coaption more likely to reflect proper zygomatic repositioning. Proper alignment of the zygomatic arch assures restoration of facial width (which tends to be increased in these injuries) while, reciprocally, restoring malar projection.

In late reconstructions, restoration of orbital rim anatomy may require osteotomy and repositioning. In situations where comminution and displacement are extensive, replacement with autogenous grafts is often necessary. Onlay grafting may be used to restore orbital contour and rim position.

\section{Mobilization of orbital contents}

The contents of the orbit are freed from the injured area by subperiosteal dissection, usually under loupe magnification. Care is taken to avoid damaging the lacrimal sac and structures in the inferior orbital fissure. Ideally, intact bony edges should be identified as the basis for orientation and to provide stable constructs on which to position grafts. This dissection can be exceedingly difficult in extensive injuries, particularly when surgery has been delayed and prolapsed orbital fat has healed to damaged mucosa in the maxillary or ethmoid sinuses, or to temporalis muscle in the temporal fossa. The orbital contents must be separated from these structures, returned and replaced in the orbit.

The intact bony landmark which is usually most difficult to identify is the posterior ledge of the remaining intact orbital floor [8]. This access greatly simplifies this dissection. The posterior rim can also be located by placing the end of an elevator against the posterior wall of the maxillary sinus (Fig. 3). By

\section{Fig. 3. Mobilization of orbital contents}

Identification of the intact posterior ledge is performed by placing an elevator against the posterior wall of the maxillary antrum and elevating it until it meets restriction. The presence of this intact bony landmark must be confirmed preoperatively by CT scanning to avoid an inadvertant injury to the optic nerve.

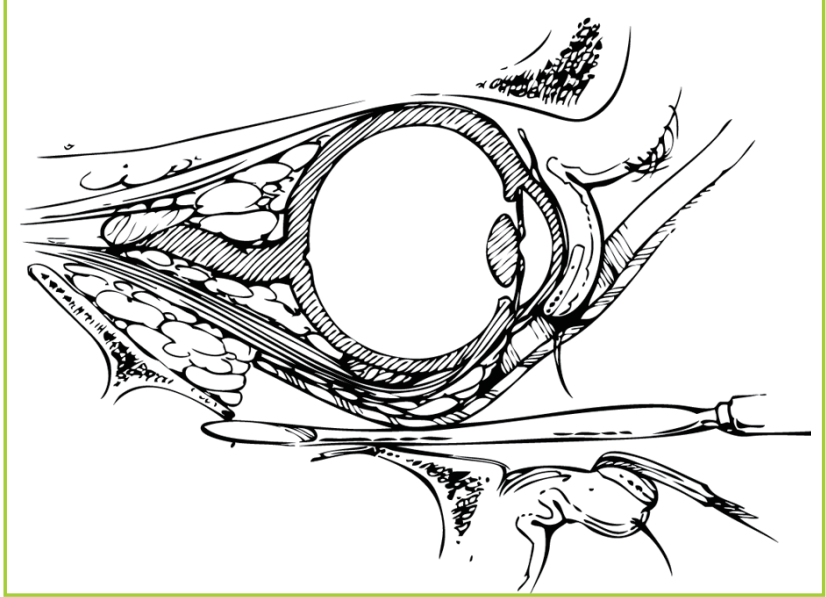


elevating the end until it meets resistance allows for identification of this rim. The ledge, which is usually $30-38 \mathrm{~mm}$ from the infraorbital rim, may be unstable.

Once the prolapsed contents of the orbit are removed from the maxillary or ethmoid sinuses, temporarily interpositioning a piece of silicone sheeting between the soft tissues and the area to be reconstructed is helpful. This maneuver prevents the soft tissues falling back into the sinus, thereby lessening their subsequent handling and allows easier control during placement of the implant or graft. Once reconstruction is complete, the silicone sheet is removed [9].

\section{INTERNAL ORBIT RECONSTRUCTION}

The internal orbit is reconstructed to restore its preinjury anatomy with the anticipation that proper globe position will result (Fig. 4). When reconstructing injuries to one orbital wall, the surgeon simply defines the defect by identifying intact bone edges and spanning the defect with an implant or auto-genous graft. Reconstruction with autogenous materials has the conceptual advantage that they will, in time, become revascularized

\section{Fig. 4. Case}

Case of a 25-year-old gentleman with significant left medial orbital wall and orbital floor fracture. The pre- and postoperative CT findings are shown. (A) Coronal preoperative view. (B) Postoperative coronal view demonstrating significant improvement in the contour of the left orbit after placement of an anatomical pre-bent medial orbital wall and floor implant. (C) Preoperative sagittal view. (D) Postoperative sagittal view.
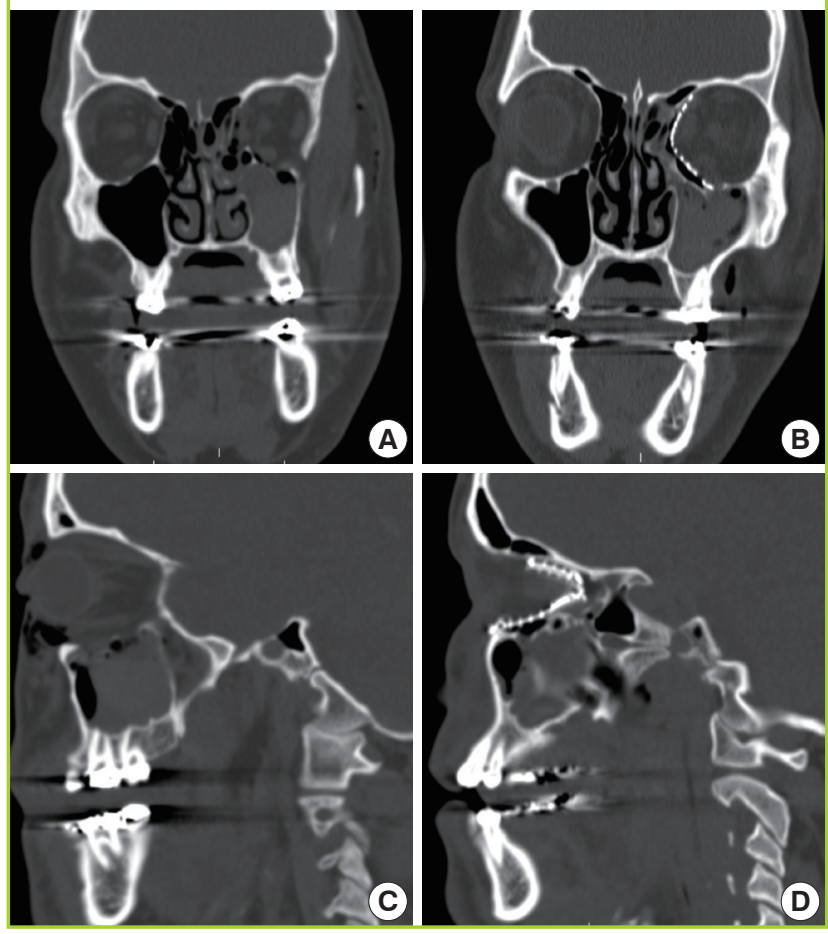

and incorporated into the skeleton, thereby resisting migration, extrusion, and infection.

Revascularization, however, also predisposes the graft towards resorption; the extent to which this occurs is unpredictable, making ultimate globe position also unpredictable. Clinical experience has shown that calvarial grafts tend to resorb less than grafts taken from other donor sites. Cranial bone grafts have more dense cortical bone than ilium or rib, which tend to be predominantly cancellous.

Experimental evidence suggests that the volume persistence of calvarial grafts may result from the fact that cortical bone is less well vascularized and hence less susceptible to osteoclastic activity than cancellous bone [10]. Unfortunately, calvarial bone is much more difficult to shape and control during internal orbit reconstruction. To avoid changes in graft shape, volume, and position, this author often uses alloplastic implants made of expanded polyethylene (Medpor, Porex Co., Atlanta, GA, USA) to reconstruct the internal orbit. This implant has a pore size which allows vascular ingrowth and some incorporation into the recipient bed. In a personal experience of 70 patients over a 4-year period, there has been no known instance of infection or graft extrusion using this material.

Injuries involving two or more walls of the orbit are problematic. Rigid fixation techniques are useful in these injuries by allowing, in effect, these complex injuries to be subdivided into a series of smaller, more manageable areas [11]. Metallic implants are attached to the orbital rim and are used to span large defects and provide a platform to support grafts for implants.

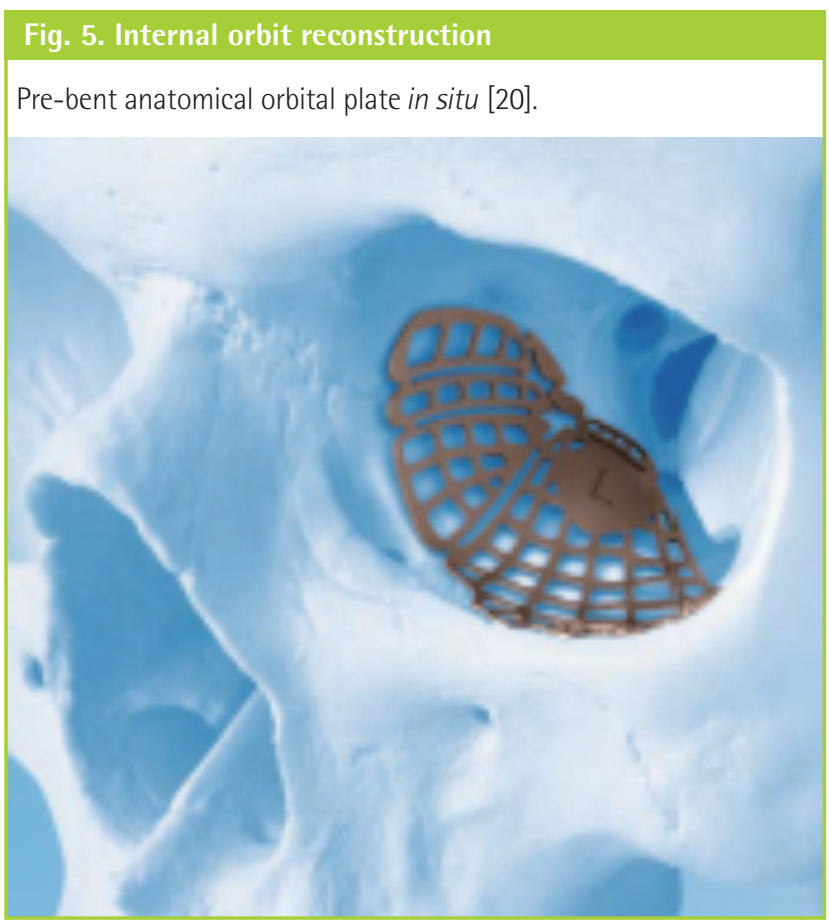


This support function can be accomplished with a number of designs (Fig. 5). The implant alone may be used to restore the internal orbital contour or may serve as a platform on which to place grafts [12]. Clinical experience has shown that prolapse of orbital soft tissues through mesh platforms has not led to motility problems or made subsequent reoperation difficult.

The utility of such metallic implants has been demonstrated in the senior author's (M.J.Y) recent experience with repair of orbital floor and medial wall fractures. An anatomical prebent titanium plate was used to reconstruct 19 medial wall fractures in 17 patients. Preliminary measurements of pre- and post-reconstruction orbital volume have shown a statistically significant improvement in the reconstructed orbital volume. Initial average orbital volume difference between the fractured and nonfractured orbit measured approximately $11 \%$ compared to $2 \%$ in the post-reconstruction volume measurements. This preliminary survey demonstrated the effectiveness of costum anatomical mesh plates in restoration of orbital contour and volume with a low complication rate.

\section{ALTERNATIVE TECHINIQUES}

Zhang et al. [13] demonstrated the use of computed tomography-based mirroring-reconstruction images of the orbit in 22 patients with late posttraumatic enophthalmos. The authors were able to fabricate anatomically adaptive titanium mesh by computer-aided design and computer-aided manufacturing techniques. Application of the implant reduced the traumainduced orbital volume increment by $65 \%$ and corrected $50 \%$ of severe late enophthalmos. Nonetheless, additional augmentation of orbital contents was required for further correction.

He et al. [14] promolgated the use of navigation-guided surgery with a $3 \mathrm{D}$ model, and titanium mesh with an alloplastic implant, for the treatment for delayed orbitozygomatic fractures with severe enophthalmos. In this retrospective review of 64 patients, good globe projection was achieved in $74.2 \%$ of the cases of the traditional surgery, $75 \%$ in the group undergoing computer-assisted 3D model surgery, and $90.9 \%$ in the navigationguided surgery group.

Although enlargement of the bony orbit is the accepted pathogenesis for late enophthalmos [15], several authors have recently attempted to prevent or correct the deformity with periorbital soft tissue augmentation. Nishi et al. [16] have used sliced costal cartilage for the treatment of late posttraumatic enophthalmos by placing grafts below the subperiosteum from a location posterior to the equatorial plane of the orbit. Lee [17] has advocated the use of autologous, diced-cartilage graft to augment the orbital-tissue volume in addition to the standard fracture-reduction methods in the acute setting.

In a recent case report, Cerveli et al. [18] demonstrated the use of retrobulbar lipofilling for correction of enophthalmos and suggested its use as a safe alternative technique for orbital volume enhancement. Bernardino [19] suggested the correction of late posttraumatic enophthalmos by using a tissue expander.

\section{SUMMARY}

Posttraumatic enophthalmos presents as a challange to the reconstrcutive surgeon given the fuctional and aesthetic considerations that relate to the orbit. Correction of late enophthalmos deformities requires intimate knowledge of the bony orbit and its contour. Wide surgical exposure and retrieval of the prolapsed orbital content into its anatomic location can facilitate restoration of the orbital shape. Given the intricate anatomy of the internal orbit, several alloplastic implants are now available for more accurate reconstruction of the orbital contour. Skillful planning and repair of late enophthalmos has been demonstrated in multiple recent studies and it is likely related to the precision with which orbital anatomy can be restored.

\section{CASE PRESENTATIONS}

\section{Case 1}

A 22-year-old man was referred for treatment 4 days after suffering a complex zygomatic and internal orbital injury after being involved in a motor vehicle accident (Fig. 6). Ocular function was normal. A preoperative CT scan showed massive disruption of the zygomatic complex as well as disruption of three walls of the internal orbit.

Reconstruction took place on the fifth day after injury using coronal, transconjunctival with lateral canthotomy, and gingival buccal sulcus approaches. The zygomaticofrontal and zygomaticosphenoid articulations were aligned as well as the zygomatic arch, infraorbital rim, and lateral buttress. Microplate fixation was used for maintaining position of the zygomaticofrontal articulation, zygomatic arch, and inferior rim. A miniplate was used to maintain position of the lateral buttress. The lateral and inferolateral portion of the orbit was reconstructed with a channel implant of expanded polyethylene. A titanium miniplate was placed in one of the prefabricated slots and fixated to the lateral orbital rim, thereby maintaining position of the orbital contents in this area and also providing support for a second implant, positioned to reconstruct the inferomedial convexity of the orbit.

\section{Case 2}

A 44-year-old man was referred 2 years after suffering a zygo- 


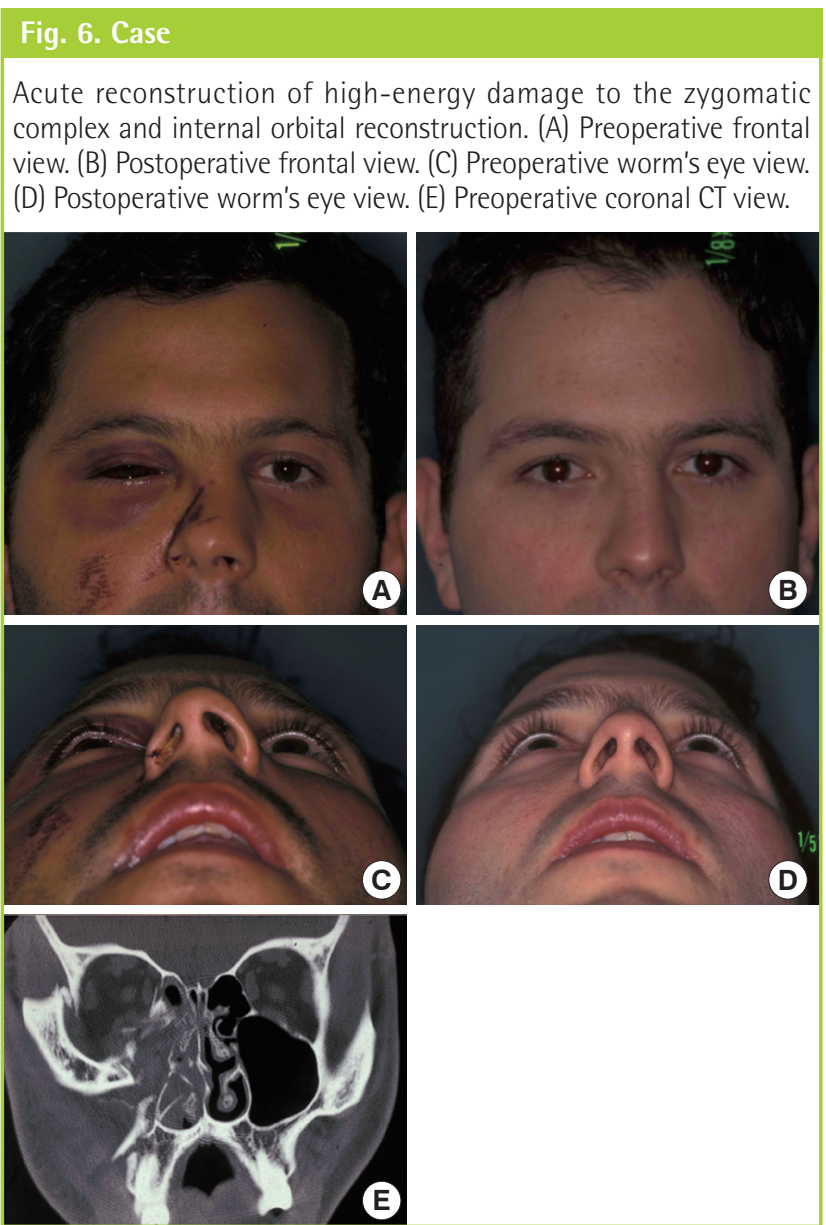

matic and heminasoethmoid fracture in a motor vehicle accident (Fig. 7). The fracture was treated acutely with open reduction and rigid internal fixation. The patient had diplopia in three fields of gaze preoperatively.

Reconstruction was accomplished through bicoronal and transconjunctival approaches with lateral canthotomy. The medial orbital wall, with its attached medial canthal ligament, was osteotomized and repositioned. The repositioned bone fragments were then fixed inferiorly with a microplate. Superiorly, the bone fragment was purchased with a transnasal wire attached to a miniscrew placed in the right superomedial orbital rim. An inferior orbitotomy was used to access and retrieve the orbital contents from the temporal fossa, the orbital floor, and the ethmoid sinuses. Vitallium mesh was used to reconstruct the internal orbit and provide a platform for expanded polyethylene implants. In this case, some residual enophthalmos persisted owing to the surgeon's failure to appwciate the increase in orbital volume resulting from anatomic replacement of the previously laterally displaced medial orbital rim and wall.

\section{Fig. 7. Case}

Late orbital reconstruction after a motor vehicle collision. (A) Preoperative frontal view. (B) Postoperative frontal view. (C) Preoperative worm's eye view. (D) Postoperative worm's eye view.
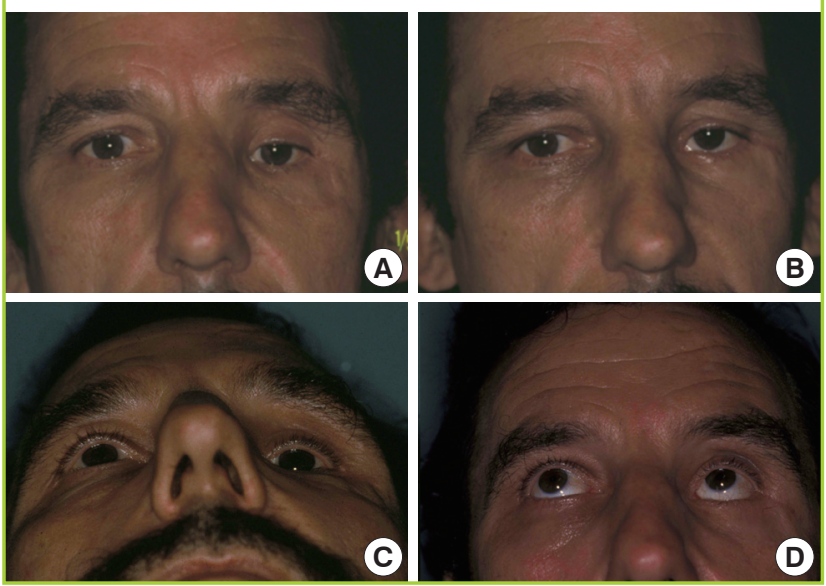

\section{REFERENCES}

1. Bite U, Jackson IT, Forbes GS, et al. Orbital volume measurements in enophthalmos using three-dimensional CT imaging. Plast Reconstr Surg 1985;75:502-8.

2. Manson PN, Clifford CM, Su CT, et al. Mechanisms of global support and posttraumatic enophthalmos: I. The anatomy of the ligament sling and its relation to intramuscular cone orbital fat. Plast Reconstr Surg 1986;77:193-202.

3. Manson PN, Grivas A, Rosenbaum A, et al. Studies on enophthalmos: II. The measurement of orbital injuries and their treatment by quantitative computed tomography. Plast Reconstr Surg 1986;77:203-14.

4. Smith RR, Blount RL. Blowout fracture of the orbital roof with pulsating exophthalmos, blepharoptosis, and superior gaze paresis. Am J Ophthalmol 1971;71:1052-4.

5. Catone GA, Morrissette MP, Carlson ER. A retrospective study of untreated orbital blow-out fractures. J Oral Maxillofac Surg 1988;46:1033-8.

6. Hawes MJ, Dortzbach RK. Surgery on orbital floor fractures: influence of time of repair and fracture size. Ophthalmology 1983;90:1066-70.

7. Wilkins RB, Havins WE. Current treatment of blow-out fractures. Ophthalmology 1982;89:464-6.

8. Tessier P. Inferior orbitotomy: a new approach to the orbital floor. Clin Plast Surg 1982;9:569-75.

9. Glassman RD, Manson PN, Petty P, et al. Techniques for improved visibility and lid protection in orbital explorations. J Craniofac Surg 1990;1:69-71.

10. Chen NT, Glowacki J, Bucky LP, et al. The roles of revascularization and resorption on endurance of craniofacial onlay 
bone grafts in the rabbit. Plast Reconstr Surg 1994;93:714 22.

11. Glassman RD, Manson PN, Vanderkolk CA, et al. Rigid fixation of internal orbital fractures. Plast Reconstr Surg 1990;86:1103-9.

12. Rubin PA, Shore JW, Yaremchuk MJ. Complex orbital fracture repair using rigid fixation of the internal orbital skeleton. Ophthalmology 1992;99:553-9.

13. Zhang Y, He Y, Zhang ZY, et al. Evaluation of the application of computer-aided shape-adapted fabricated titanium mesh for mirroring-reconstructing orbital walls in cases of late posttraumatic enophthalmos. J Oral Maxillofac Surg 2010;68:2070-5.

14. He D, Li Z, Shi W, et al. Orbitozygomatic fractures with enophthalmos: analysis of 64 cases treated late. J Oral Maxillofac Surg 2011 Jul 11 [Epub]. http://dx.doi.org/10.1016/ j.joms. 2011.02.041.

15. Manson PN. Facial fractures. In: Mathes SJ, editor. Plastic surgery. Philadelphia, PA: Elsevier; 2006. p. 285-6.

16. Nishi $Y$, Kiyokawa K, Watanabe K, et al. A surgical treatment of severe late posttraumatic enophthalmos using sliced costal cartilage chip grafts. J Craniofac Surg 2006;17:673-9.

17. Lee JW. Treatment of enophthalmos using corrective osteotomy with concomitant cartilage-graft implantation. J Plast Reconstr Aesthet Surg 2010;63:42-53.

18. Cervelli D, Gasparini G, Moro A, et al. Retrobulbar lipofilling to correct the enophthalmos. J Craniofac Surg 2011;22:191822.

19. Bernardino CR. Correction of late posttraumatic enophthalmos using a tissue expander. Ann Plast Surg 2006;57: 477.

20. Synthes. MatrixORBITAL: anatomical reconstruction of medial wall and orbital floor fractures [Internet]. West Chester, PA: Synthes; c2011 [cited 2011 Dec 23]. Available from: http://www.synthes.com/MediaBin/International\%20DATA/036.000.496.pdf. 